\title{
Attempted rapid elbow flexion movements in patients with athetosis
}

\author{
MARK HALLETT, ${ }^{*}$ NORBERTO ALVAREZ† \\ From the Section of Neurology, Department of Medicine, Brigham and Women's Hospital* and the \\ Neurology-Seizure Control Program, Wrentham State School-Children's Hospital Medical Center $\dagger$ and the \\ Department of Neurology, ${ }^{*} \dagger$ Harvard Medical School, Boston, USA
}

SUMMARY Voluntary rapid elbow flexion movements were studied in 14 patients with athetosis on the basis of cerebral palsy. When the movement was attempted with one arm, other muscles inappropriate for the task, such as muscles in the opposite limb, were also activated. EMG activity of the biceps and triceps was analysed in detail, and the patterns seen in the different patients were divided into six groups: (1) The normal "ballistic" triphasic pattern, with bursts of normal duration, alternating in biceps and triceps, but the triceps might be activated first, causing the limb to extend rather than flex, (2) The triphasic pattern, with bursts of long duration, (3) Repetitive cycles of the triphasic pattern with particularly long antagonist bursts, apparently limiting the movement in each cycle, (4) Long bursts synchronous in agonist and antagonist muscles, (5) Continuous activity of the agonist, with reduction in activity of the antagonist, (6) Failure to be able to do the task. The pathophysiology of athetosis is that voluntary movement is characterised by excessive muscular activity, most prominently in inappropriate muscles, both extraneous to the task and directly antagonistic.

The term athetosis means "without fixed position" and brings to mind a type of involuntary movement characterised by "two or more abnormalities in posture, between which there is intermittent change or fluctuation." A critically important disability, however, for the patient with athetosis is the derangement of voluntary movement. With attempts at voluntary movement the athetosis seems to increase in intensity, not only in the body part attempting the movement but in other body parts as well. As Denny-Brown described it, "the willed effort of the patient results first in increase in the dystonia associated with the athetosis, often of antagonists of the movement that is attempted." 1

In an effort to learn more about the physiology of athetoid voluntary movement, we have studied the electromyographic patterns associated with attemp-

Address for reprint requests: Mark Hallett, MD, Section of Neurology, Brigham and Women's Hospital, 75 Francis Street, Boston, MA 02115, USA.

Presented in part at the American Neurological Association meeting in Boston, MA, September, 1980.

Received 21 July 1982 and in revised form 14 February 1983 Accepted 4 March 1983 ted rapid elbow flexion movements in patients with athetosis associated with cerebral palsy. The normal electromyographic pattern of the ballistic movement and its physiology have been well studied. ${ }^{2-5}$ The initial part of the electromyographic pattern is "triphasic" with a discrete burst of activity in biceps, followed by a burst in triceps while the biceps is silent, and followed by return of activity in biceps, often in the form of a burst. The first biceps burst sets the limb in motion; its duration is fixed between $50-100 \mathrm{~ms}$ and its amplitude is modulated for different movements, such as movements of different distance. The first triceps burst helps to stop the limb at the end-point of movement, and its duration is similarly fixed between $50-100 \mathrm{~ms}$.

\section{Methods}

The 14 patients were all from the Wrentham State School (Table). There were nine men and five women ranging in age from 25-68 yr and all suffered with athetosis due to cerebral injury early in life. Most patients had borderline intelligence and all understood the task quite clearly and gave informed consent to participate. Neurological examination of the arm studied was quantified in the following way. Strength of biceps and triceps was assessed on the 0-5 scale described in Aids to the Examination of the Peripheral 
Table Clinical characteristics of patients

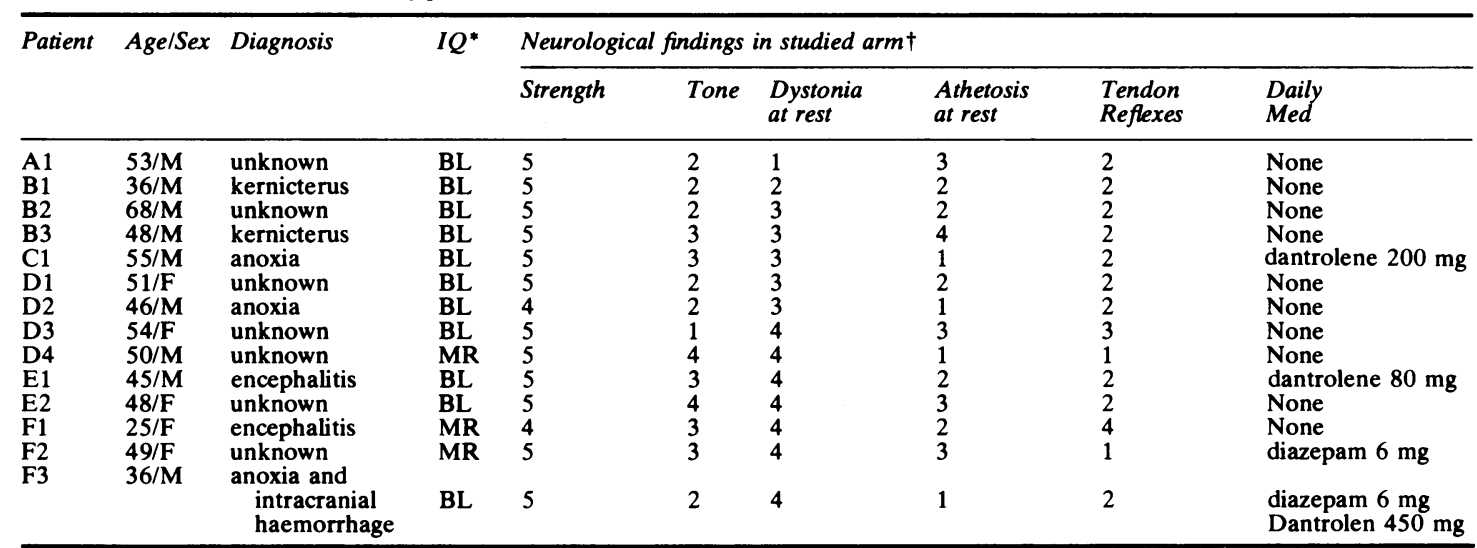

${ }^{*} \mathrm{BL}=$ borderline; $\mathrm{MR}=$ moderate retardation

+See Methods for quantification of strength, tone, dystonia, athetosis, tendon reflexes.

Nervous System (Her Majesty's Stationery Office, London, 1976). Tone, the resistance to passive stretch at the elbow, was assessed as (0) none, (1) reduced, (2) normal, (3) mild-moderate increase and (4) moderate-severe increase. Dystonia, the tendency for spontaneous fixed postures, and athetosis, the amount of apparently spontaneous writhing movement, were assessed with the patient relaxed sitting in a chair as (0) none, (1) minimal, (2) mild, (3) moderate and (4) severe. Tendon jerks of biceps and triceps were assessed as (0) absent, (1) decreased, (2) normal, (3) mildly increased and (4) markedly increased.

The procedure for studying elbow flexion has been described previously. ${ }^{2}$ Briefly, subjects sat in a chair and their dominant arm was strapped into a light-weight brace with a potentiometer incorporated into a low friction joint at the elbow. The angular position of the elbow was converted to a voltage and was displayed to the patient as the vertical position of a horizontal line on an oscilloscope. The shoulder was abducted to $90^{\circ}$, the forearm was fully supinated and the starting angle of the elbow was $120^{\circ}$. Following a verbal command subjects attempted to flex their elbows as rapidly as possible to $80^{\circ}$ by moving the line on the oscilloscope from one designated position to another. Surface EMG from biceps and triceps as well as angular position of the elbow were recorded.

\section{Results}

In all patients attempts to flex the elbow resulted in unnecessary, unwanted muscle contractions throughout the entire body. This excessive muscle activity occurred at the same time as the voluntary movement and was often quite forceful (fig 1). EMG activity in antagonist muscles was synchronous. Observations of the spontaneous activity of the patients suggested that much of the involuntary "athetoid movement" was in fact this inappropriate muscle activity brought out by voluntary movement.
As the patients attempted to make voluntary movements the amount of athetosis increased. This physiological process of excessive generalisation of the motor command can be called "overflow".

The patterns of activation of the biceps and triceps (in the voluntarily innervated arm) divided the patients into six groups, called $\mathrm{A}-\mathrm{F}$ in the Table.

The first pattern (group A) was essentially normal with bursts of EMG activity of normal duration occurring alternately in the antagonist muscles (fig 2). Occasionally, following the verbal command to flex the elbow, the elbow would rapidly extend. This behaviour came as a surprise to the patient who could not explain it.

The second pattern (group B) was characterised by maintained appropriate reciprocal activity in biceps and triceps, but with durations of bursts; particularly the first biceps burst, longer than the normal upper limit of normal of $100 \mathrm{~ms}$ (fig 3). On some trials the elbow would unexpectedly extend rather than flex just as in the first group. Two of the three patients (B1 and B3) frequently produced a

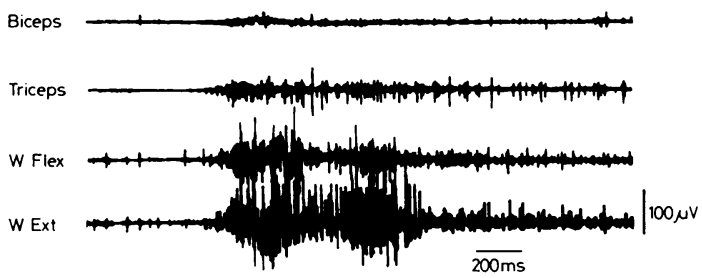

Fig 1 EMG activity in left arm muscles of patient D3 during a right elbow flexion movement. The movement of the right arm occurred at approximately the same time as the large bursts of activity in the left arm muscles. 
(a)

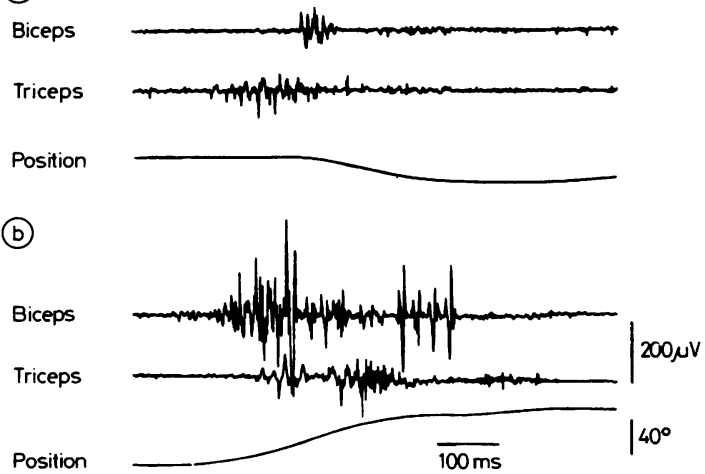

Fig 2 EMG activity in two single trials of attempted rapid elbow flexions for patient A1. The movement is accomplished normally in $B$, while in $A$ the elbow extended in error. (The duration of the first agonist burst in $B$ is prolonged which was atypical for this patient.)
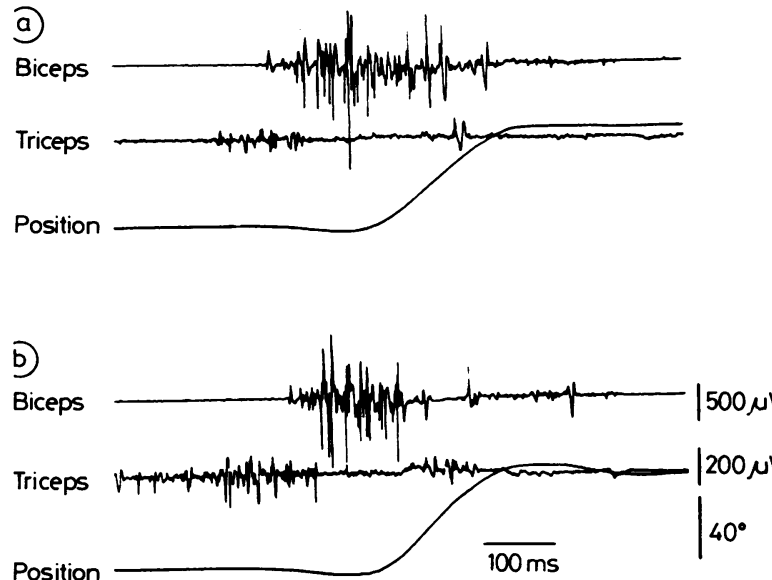

Fig 3 EMG activity in two single trials of attempted rapid elbow flexions for patient B3. Note reciprocal activity in the muscles, but that the first biceps burst is prolonged and that a burst of triceps activity occurs prior to the first burst causing the elbow to transiently extend.

burst of activity in the triceps before the first burst in biceps. This triceps burst caused the elbow to extend slightly before the main flexion movement.

The third pattern (group C), represented by only one patient, was characterised by rhythmic bursts of EMG activity at about $2 \mathrm{~Hz}$ (fig 4). For this group and subsequent groups, although the patients were clearly trying to make rapid movements, the movements were in fact slow and cannot be considered "ballistic". For this patient the movement took 1-2 s to accomplish. Each "beat" of the rhythmic

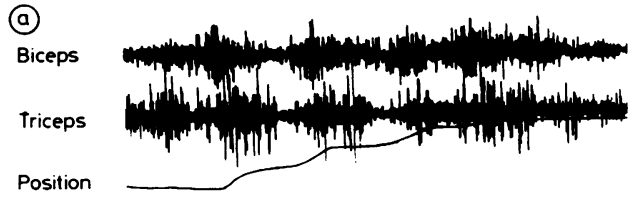

(b)

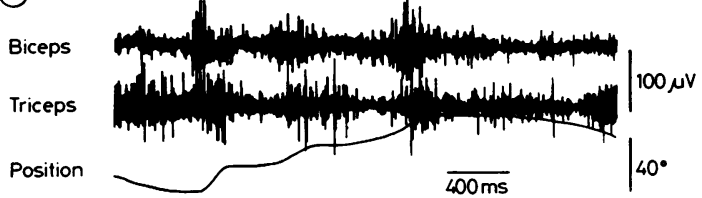

Fig 4 EMG activity in two single trials of attempted rapid elbow flexions for patient C1. Biceps and triceps activity occur in a rhythmic $2 \mathrm{~Hz}$ tremor.

(a)

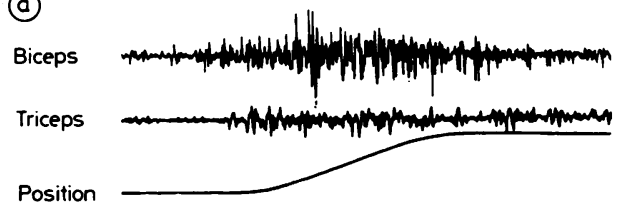

(b)

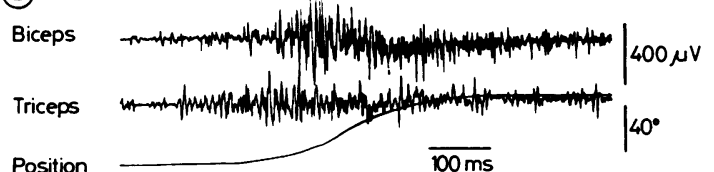

$\overline{100 \mathrm{~ms}}$

Fig 5 EMG activity in two single trials of attempted rapid elbow flexions for patient $D 1$. The two antagonist muscles are active synchronously.

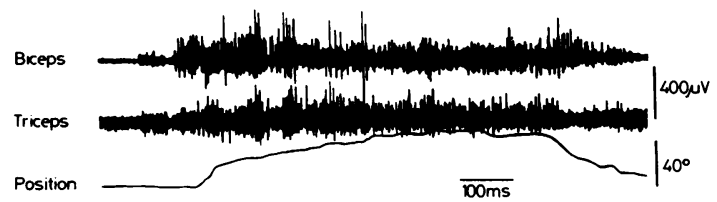

Fig 6 EMG activity in a single trial of attempted rapid elbow flexion for patient D2. There is co-contraction of the antagonist muscles with some superimposed $2 \mathrm{~Hz}$ tremor.

tremor produced a small increment of flexion. Biceps activity would begin and in approximately $100 \mathrm{~ms}$ triceps activity would start, overlapping with the end of the biceps burst. The triceps burst was usually longer in duration than the biceps burst, but at least equal to it, and the functional consequence seemed to be that the movement was halted.

The fourth pattern (group D) was characterised 

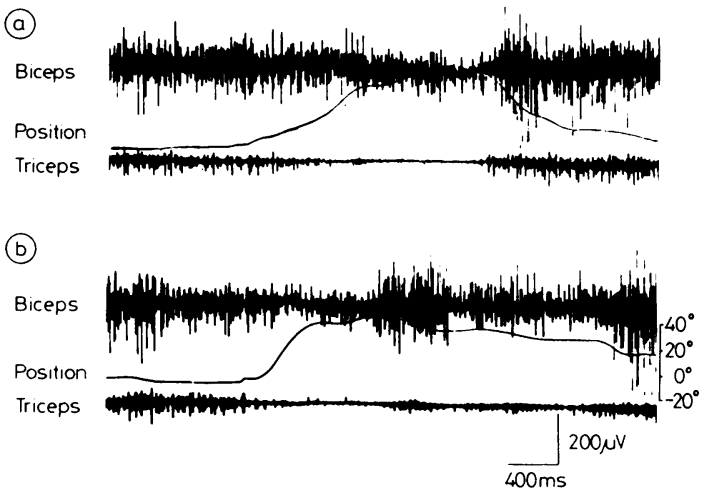

Fig 7 EMG activity in two single trials of attempted rapid elbow flexions for patient E1. Flexion is accomplished by relaxation of the triceps.

by prolonged synchronous activity in the antagonist muscles (figs 5 and 6 ). This co-contraction activity might begin in the biceps (fig 5A) or the triceps (fig 5B). One patient (D2, fig 6) moved only very slowly and frequently exhibited a $2 \mathrm{~Hz}$ tremor on top of the co-contraction pattern. The EMG activity of the tremor component often appeared completely synchronous, but could exhibit the pattern of group $\mathrm{C}$ where the biceps would begin slightly earlier.

The fifth pattern (group E) was seen in two patients who had considerable EMG activity at rest. Movements were difficult to make, and the patients seemed to be struggling to start the movement and carry it to completion. Flexion was not accomplished by increasing biceps activity, but by reduction in triceps activity (fig 7). With reduction in triceps activity, flexion could be accomplished by maintained or even slightly reduced biceps activity.

The sixth pattern (group F) was long bursts of co-contraction activity in the two antagonist muscles with inability to accomplish the task. The arm moved almost randomly without any real control.

\section{Discussion}

The electromyographic patterns associated with athetoid movements were established some time ago to be characterised by rather prolonged bursts of activity occurring synchronously in antagonist muscles, ${ }^{6-8}$ similar to what is seen with dystonia. ${ }^{9}$ The observation stressed here, which has been often overlooked, is that the involuntary activity is often produced as an overflow phenomenon from an attempted voluntary movement. It is possible, but difficult to prove, that all involuntary movement is a result of overflow since even in an apparently relaxed person there are postural movements and adjustments that are continuously ongoing.

A major facet of the pathophysiology of voluntary movement in patients with athetosis is also overflow, with the excessive innervation occurring in the antagonist muscles in a variety of patterns. The minimal abnormality, occurring regularly or irregularly in groups $\mathrm{A}$ and $\mathrm{B}$, was a burst of EMG activity in the antagonist prior to the first agonist burst. Such a pattern is rarely seen in a normal subject who behaves as if he is "winding up" for the movement similar to the back-swing of the baseball batter. When the pattern is seen normally, however, it is not of large magnitude and is not persistent. The typical normal pattern for the antagonist muscle is to be inhibited after the signal to move. ${ }^{5}$ For the patient with athetosis, the minimal functional deficit from initial antagonist activity would be prolongation of reaction time, a phenomenon recognised in patients with athetosis. ${ }^{10}$ The maximal functional deficit is having the limb go in the direction opposite that which is intended, a bizarre phenomenon long recognised. ${ }^{6}$

A second pattern of excessive antagonist activity is seen in group $\mathrm{C}$ who demonstrated a $2 \mathrm{~Hz}$ action tremor in trying to accomplish the movement. With each beat of tremor the antagonist activity came in strongly and before the agonist activity had finished. The apparent functional consequence is that the amount of movement in each cycle is limited, multiple cycles are needed to complete the movement, and the movement is slowed. Prolongation of movement time, which characterised most of our patients, is a well-known phenomenon in patients with athetosis ${ }^{11-13}$ and also dystonia. ${ }^{14}$

The third pattern of overflow to the antagonist is co-contraction, and this characterised groups D, E and $\mathrm{F}$ comprising nine of the fourteen patients. Co-contraction was noted clinically by Wilson who described the phenomenon as "loss of reciprocal innervation". ${ }^{15}$ Synchronous activity in antagonist muscles in electromyographic studies of voluntary movement has been noted previously in patients with athetosis ${ }^{6}$ and also dystonia. ${ }^{14}$ Some cocontraction can be present normally in both ballistic and slower, ramp movements, but the magnitude is not very large and it never seems to slow down the movement as it seems to do for the athetoid patients. Activation of the antagonist was very intense in some patients and it appeared as if the patients were fighting against an outside force in order to accomplish the task. Often, the harder they tried, the more the antagonist was activated. Patients in group $\mathrm{E}$ were able to achieve a favorable relationship between agonist and antagonist by a reduction of activity in both muscles suggesting 
reduced effort. The total failure of patients in group $F$ was certainly due in part to this excessive antagonist activity.

An abnormality in addition to the excessive activity in the antagonist is the prolongation of duration of initial agonist firing which occurred in all patients except the one in group $A$. To a certain extent, at least in group $B$, this might be due to spasticity since spasticity is often associated with the athetosis and injury to the pyramidal tract can give rise to prolongation of the first agonist burst. ${ }^{16} 17$ For most of the patients, however, prolonged agonist activity was probably due in large part to the fact that the movements were quite slow despite the attempt to move rapidly. Slow movements are characterised by prolonged, continuous activity in the agonist. ${ }^{5}$ Normally there may be some co-contraction of the antagonist in slow movements, but this would never be to the extent seen here where antagonist activity clearly limits the progress of the movement.

Athetosis and dystonia are clearly related involuntary movements and our patients exhibited both. As can be appreciated from the table, the degree of impairment of voluntary movement in our patients correlated better with the amount of spontaneous dystonia than with the amount of spontaneous athetosis.

The location of the lesions responsible for the athetosis in our patients is not known. C. Vogt ${ }^{18}$ was the first to implicate the striatum as the site of the lesion in "double-athetosis", a term which refers to bilateral athetosis which is the descriptive category for our patients. Carpenter ${ }^{19}$ reviewed the world's pathological literature of 71 cases of athetosis including 34 cases of double athetosis. He concluded that double athetosis could result from bilateral lesions in the striatum or globus pallidus, although frequently other lesions in the nervous system might be present. The most common condition was status marmoratus (état marbré) of the striatum. More recently Dooling and Adams ${ }^{20}$ reported a detailed pathological investigation of several cases with the related disorder of posthemiplegic athetosis and concluded that the responsible lesion was in the striatum. On the basis of this evidence we presume our patients had basal ganglia lesions.

The derangement of movement seen in our patients with athetosis is compatible with our previously proposed hypothesis of the role of the basal ganglia in normal movement. ${ }^{21}$ The command signal for a normal movement must specify the muscles to be activated, including the extent of their activation and the timing of the muscle contractions. We have suggested that the basal ganglia help select the muscles to be activated and energise them appropriately. The evidence for this proposal has been that patients with Parkinson's disease, who have one type of derangement of basal ganglia function, select inappropriately few muscles for a movement and do not energise them adequately. Synergistic muscle activity such as arm swing when walking is reduced, and antagonist muscles do not cocontract. ${ }^{2}$ Patients with athetosis have the opposite problem; they innervate too many muscles with too much power. This overflow into even inappropriate synergists is interpreted as the involuntary movement of athetosis. Overflow extends to the antagonist of the movement and seriously disrupts it causing it to be slowed and clumsy. Hence, it appears that deranged basal ganglia influences can adversely affect the timing of a movement which (by our own hypothesis) is ordinarily set by the cerebellum.

We would agree with Denny-Brown that athetosis represents a "degradation of movement". ${ }^{1}$ In his view, athetosis reflects the "lack of fine cortical control" and "represents the unrestrained activity of the reflex direction of movement". The reflexes set up the postures between which the athetoid movements occur. As had been pointed out to us recently by RK Byers, however, some subcortical reflexes (such as the tonic neck reflex) of children with athetosis, may be smooth and efficient even after the athetosis develops. We would propose that athetoid movements represent movement overflow from movements which arise cortically and are degraded from lack of the basal ganglionic contribution.

\section{References}

${ }^{1}$ Denny-Brown D. Clinical symptomatology of disease of the basal ganglia. In: Vinken PJ, Bruyn GW, eds. Handbook of Clinical Neurology Amsterdam: North Holland Publishing Co., 1968;133-72.

${ }^{2}$ Hallett M, Khoshbin S. A physiological mechanism of bradykinesia. Brain 1980;103:301-14.

${ }^{3}$ Hallett M, Marsden CD. Ballistic flexion movements of the human thumb.J Physiol (Lond) 1979;294:33-50.

${ }^{4}$ Hallett M, Marsden CD. Physiology and pathophysiology of the ballistic movement pattern. In: Desmedt JE, ed. Progress in Clinical Neurophysiol Basel: Karger, 1981;9:331-46.

${ }^{5}$ Hallett M, Shahani BT, Young RR. EMG analysis of stereotyped voluntary movements in man. $J$ Neurol Neurosurg Psychiatry 1975;38:1154-62.

${ }^{6}$ Hoefer PFA, Putnam TJ. Action potentials of muscles in athetosis and Sydenham's chorea. Arch Neurol Psychiatry 1940;44:517-31.

' Putnam TJ. The diagnosis and treatment of athetosis and dystonia. J Bone Joint Surg 1939;21:948-57.

${ }^{8}$ Thiebaut F, Isch F. Etude clinique cinématographique et bioélectrique du quatre formes d'athétose. Rev Neurol (Paris) 1952;87:26-41. 
${ }^{9}$ Herz E. Dystonia. I. Historical review; analysis of dystonic symptoms and physiological mechanisms involved. Arch Neurol Psychiatry 1944;51:305-18.

${ }^{10}$ Neilson PD. Voluntary control of arm movement in athetotic patients. J Neurol Neurosurg Psychiatry 1974;37:162-70.

"Andrews CJ, Burke D, Lance JW. The comparison of tremors in normal parkinsonian and athetotic man. $J$ Neurol Sci 1973;19:53-61.

${ }^{12}$ Lindsley DB. Electromyographic studies of neuromuscular disorders. Arch Neurol Psychiatry 1936;36:12857.

${ }^{13}$ Neilson PD. Measurement of involuntary arm movement in athetotic patients. J Neurol Neurosurg Psychiatry 1974;37:171-7.

${ }^{14}$ Yanagisawa N, Goto A. Dystonia musculorum deformans; analysis with electromyography. J Neurol Sci 1971;13:39-65.

${ }^{15}$ Wilson SAK. Disorders of motility and muscle tone, with special reference to the striatum. Lancet $1971 ; 2: 215-9$.
${ }^{16}$ Angel RW. Electromyographic patterns during ballistic movements in normals and in hemiplegic patients. In: Desmedt JD, ed. Progress in Clin Neurophysiology Basel: Karger, 1981;9:347-57.

${ }^{17}$ Hallett M. Ballistic elbow flexion movements in patients with amyotrophic lateral sclerosis. J Neurol Neurosurg Psychiatry 1979;42:232-7.

${ }^{18}$ Vogt C. Quelques considérations générales à propos du syndrome du corps strié. J Psychol Neurol (Lpz) 1911;18:479-88.

${ }^{19}$ Carpenter MB. Athetosis and the basal ganglia; review of the literature and study of forty-two cases. Arch Neurol Psychiatry 1950;63:875-901.

${ }^{20}$ Dooling EC, Adams RD. The pathological anatomy of posthemiplegic athetosis. Brain 1975;98:29-48.

${ }^{21}$ Hallett M. Physiology and pathophysiology of voluntary movement. In: Tyler HR, Dawson DM, eds. Current Neurology 2. Boston: Houghton-Mifflin, 1979;35176. 